\title{
Supply chain management: Solutions to improving the competitive advantage of small- and medium-sized enterprises: The case of Danang City
}

\author{
LE THI MINH HANGa
}

${ }^{a}$ Danang University of Economics

\begin{tabular}{l} 
A R T I C L E I N F O \\
\hline Received 1 Nov. 2015 \\
Revised 20 Dec. 2015 \\
Accepted 1 Jan. 2018 \\
Available online \\
12 January 2018 \\
JEL classifications: \\
D22; L53; P42 \\
KEYwORDS \\
Supply chain \\
management \\
Small- and medium-sized \\
enterprises \\
SCM practice \\
SCM measurement
\end{tabular}

A B S T R A C T

Supply chain management (SCM) has been proven to improve the competitive advantage, and increase the effectiveness of operation in small and medium sized enterprises (SMEs) (Chin et al., 2012). This study investigates the measurement of SCM practice in Vietnam with the sample of 148 SMEs in Danang. The research findings exhibit the humble degree of SCM practices within these firms. These activities are in the primary form of SCM practice as supplier's quality management, customer interaction, and customer satisfaction measurement. The findings also indicate the limitations in practicing SCM in Danang SMEs, and propose implications in policy adjustment to promote SCM practices and advance the competitive advantages of SMEs.

a Email: hang.Itm@due.edu.vn 



\section{Introduction}

Supply chain management is a new managerial concept that provides values for organization. Cigolini et al. (2004) stated the comtemporary context of competition mainly in the supply chain level rather than individual firms. As a result, organizations should acknowledge the mindset that they compete as the nodes of a chain against others.

Studies worldwide asserted the positive influences of SCM on improving competitive advantage, or enlarging the organizational effectiveness, for instance, the study on the relationship of the adaptability and the integration of supply chain, with the firm's effectiveness (Sukati \& Hamid, 2012); the influences of SCM tactics planning on the effectiveness (Okongwu et al., 2016); or the investigation on the causal relationship of SCM and organizational financial efficiency (Chang et al., 2016).

A number of research focused on SCM in particular SME sector including the study on the features of SCM in SMEs (Chin et al., 2012; Gourova, 2010); research that aims to propose a research model on SCM particularly in SMEs (Levy, 2001; Udomleartprasert, 2003); or the studies on the benefits of SCM to SMEs (Chen \& Paulraj, 2004; Lenny Koh, 2007; Nguyen, 2010; Chin et al., 2012).

A variety of studies has investigated the causal relationship of SCM to organizational effectiveness. SCM is a complex concept, that involves an abundance of related actors (Chopra \& Meindl, 2014), confined the issues in both strategic and tactics level, even the topic of collaboration and information \& communication technology (ICT) application (van der Vaart \& van Donk, 2008). The complexity drew the attention of scholars to construct a scale to measure the SCM practices in an organization (Tan, 2001; Li et al., 2005). On this basis, in order to identify the limitations and remaining issues in practicing SCM, the studies to contribute the empirical evidence on the status quo of SCM practices in organizations were carried out (Olhager \& Selldin, 2004; Sukati et al., 2011).

In Vietnam, the studies on SCM are still in the infant stage. Recently, this topic has raised the interest among scholars in Vietnam, prominently including the studies on value chain especially the agri- \& aqua-cultural product value chain of Vo and Nguyen (2013) and Ha (2012), or the research on the application of SCM in individual organizations or specific industry by theses at master and PhD levels. However, the studies, following the worldwide acknowledged scientific research methodology, to describe the degree of SCM in a firm or to measure the influences of SCM on the organizational performance are in absence.

This study provides the firsthand empirical evidence in the field of SCM measurement in Vietnam. The paper also concentrates in investigating the status quo of practicing SCM in SMEs in Danang. The research findings contribute the foundations to progress the SCM practices and promote the competitive advantage of SMEs. This study will be the profound premise for ulterior studies on SCM in Vietnam. 


\section{Literature review}

\subsection{Supply chain manangement in SMEs}

Supply chain manangement (SCM) was established from the radical change of logistic function. SCM was defined as the management of business activities, the management of internal relationship, relationships with supplier, suppliers of suppliers, customers of the entire chain and the general management over the chain (Harland et al., 1999). New and Payne (1995) suggested SCM as the connection of organizational border-crossing processes including the input supplying, production and the ending customers. Other scholars extended the SCM concept to the aspect of recycling or reusing processes (Baatz, 1995; cited in Tan, 2001); or focused on the potential management of suppliers as technical issues to create the competitive advantage (Farley, 1997, cited in Tan, 2001). Overall, SCM is the managment of directly or indirectly relevant unit, in order to satisfy the customer needs and maximize the total value of the chain (Chopra \& Meindl, 2014).

In terms of SMEs, SCM practices implementation maintains the differences in comparison with large enterprises due to their size. Chin et al. (2012) proposed that SCM practices within SME consist of both the difficulties and advantages in confrontation with the sizeable firms. SME was supposed to be agile, with better adaptability to the business environment. SMEs implemented SCM promptly due to the more simplistic structure, flexibly adaptable culture (Gourova, 2010), nimble internal communication \& cross-function groups (Aragón-Correa \& Alberto, 2008), and the ease in promotion and better developed unofficial communication (Levy, 2001). SMEs were also agile in the adoption of renovation and innovation (Acs, 1991), flexibility in enforcement, simplicity in management, and internal co-operation (Lazarica, 2009). However, SMEs withstood the disadvantages in terms of capacity in techniques and information, lack of knowledge and technical knowhow, and the tendency to be dependent on the suppliers (Ellegaard \& Chris, 2006). The drawbacks inhibited the SCM practices in SMEs. De Toni and Nassimbeni (1996) compared the differences in implementing SCM between SMEs and sizeable enterprises based on five elements, comprising: (i) competitive advantages; (ii) strategies; (iii, iv) external and internal management structure; and (v) the purposes of SCM process. These differences laid the basis for the researchers to suggest their models to investigate the SCM practices in SMEs.

Levy (2001) proposed a model based on the strategic objectives and the firm's postition in the relationship with the entire chain. Strategic objectives emphasized on the organizational means of competition in the chain: low-cost or value added operations. The firm's postition in the relationship with the entire chain implied the organizational power of negotiation over their customers (Kalafatis et al., 2000). The firm's strategy on the chain varied depending on these two elements. Udomleartprasert (2003) inferred the limited negotiation capability of SMEs over the massive firms because of their size. The collaboration of SMEs might be a solution to extend their power. Besides the alliances, SMEs 
can co-operate to establish the sharing hub of supplying, manufacturing, distributing, and other resources.

\subsection{Benefits of SCM to SMES}

The ultimate purpose of SCM is to supply the correct product, with the correct quantity and quality to the correct customer, just in time with the correct price (Basher, 2010, cited in Chin et al., 2012). In short term, the benefits of SCM to SMEs are to improve the effectiveness of manufacturing as decreasing the inventory (Koh et at., 2007; Chin et al., 2012) to shorten the production installation stage (Chen, 2004; Koh, 2007; Chin et al., 2012), to increase the accuracy of forecasting (Mohanty, 2005), to enhance the productivity, reducing the cost of manufacturing, improving the effectiveness of internal production (Chen, 2004; Koh et al., 2007; Bidgoli, 2010). SCM facilitated the relationship of SMEs with their suppliers and customers as promoting the co-operative relationship with the suppliers(Chen, 2004; Chin et al., 2012); improvement in customer service and customer relationship (Chin et al., 2012); enhancement in distribution processes; improving the punctuality in delivery and shortening the delivering period (Chen, 2004).

Myriad studies emphasized the positive influences of SCM on SME performance. Choon et al. (2002) clarified the effect of SCM enhancement on enlarging the market share and customer satisfaction. Halley (2010) stated the inducement of SCM practices on maintaining customer relationship in the study with Canadian SMEs. Sukati et al. (2011), in their study in Malaysia, further elaborated the relationship of SCM practices on firm's competitive advantages. Recently, Chardine-Baumann and Botta-Genoulaz (2014) bolstered the benefits of SCM practices not only on organizational performance but also on firm's social responsibilities.

\subsection{Studies on SCM practices}

It is challenging to conduct the studies that describe or measure SCM practices as SCM is a complex procedure, involving a large number of actors, from the suppliers, to the manufacturers, the distributors and the ending customers. In practical research, scholars have suggested a considerable amount of models, in order to investigate the degree of SCM practices in organizations. A selec few of empirical studies were characterized with the integration of logistic and inventory management among partners (Alvarado \& Kotzab, 2001); or the separate operations as purchasing, selection, supplier management, supplier relationship (Banfield, 1994). Others described SCM with the firm's internal operations as total quality management, efficient production management, internal integration (Tan, Lyman, \& Wisner, 2002; Pagell, 2004). Van der Vaart and van Donk (2008) reviewed the body literature of SCM practice studies with 33 articles from the journals with high prestige and summarized three dominant fields of research involving SCM, such as describing the pattern of relationships among organizations, their suppliers and customer including the supplier visting, meeting or direct interactions; supplier assessment and management; 
investigating the attitudes of the firms toward their customers and suppliers, involving willingness to maintain the long-term relationship with supplier; the firm's accountability to the suppliers; and measuring practices including the tangible activities or techniques to establish the relationship with the suppliers and customers.

Donlon (1996) initiated the revolution in studies on SCM practices with the definition of SCM practices as the collaboration with suppliers, utilizing the external forces in order to shorten the production cycle and facilitate the constant manufacturing, and information sharing. Tan, Kannan, and Handfield (1998) indicated SCM practices as the purchasing activities, quality management and customer relationship management. Tan (2001) extended the concept of SCM practices to the integration of material flow, information flow among suppliers, manufacturers and customers and the postponement of mass production. Tan et al. (2002) asserted that SCM practices include the internal integration within the chain, its characteristics, information sharing, customer relationship management, quality management and just-in-time production capability.

Li et al. (2005) implemented the study in order to contribute a measurement of SCM practices. According to these authors, SCM is a set of activities and techniques used to effectively manage firm's supply chain. SCM practice is a multi-array concept involving the suppliers, customers and the internal part of an organization. The concept also considers the common principles to establish the relationship with partners, the techniques used to manage supply chain, measured by six factors: (i) strategic supplier partnership; (ii) customer relationship; (iii) information sharing; (iv) information quality; (v) internal lean practice; and (vi) postponement. Li et al. (2006) refined the scale by excluding the two factors: internal lean practice and postponement. Lately, Lopes de Sousa Jabbour (2011) analyzed the previous studies, integrated the available scale in an attempt to propose a measurement of SCM practices with four factors: (i) supply chain integration; (ii) information sharing; (iii) strategic relationship with customers and suppliers; and (iv) support customer order.

Studies on SCM practices are favourable in the field of SCM research, especially in the investigation into the influence of SCM on firm's effectiveness.

\section{Research method}

\subsection{Research sampling $\mathcal{E}$ methodology}

Collecting data of SMEs, especially in Vietnam, is challenging. This is the issue that limits the number of intensive studies on the operation of enterprise. The paper was contributed by the mutual support with the New Enterprise Association in Danang, an association with over 530 members from the top manager and leaderboard of local enterprise community, in investigating the contemporary context of SCM practices among SMEs. The questionnaire was handled in the form of a Google Docs application, and the links to the questionnaires 
sent by email. The response rate was not as high as estimated, with 173 out of 530 forms issued.

\subsection{Scales}

SCM practices involves the tangible operations and techniques used in the supply chain, for instance, data and information sharing, data transition within the chain, and cooperation in planning or packaging (van der Vaart \& van Donk, 2008). Literature review indicated the lack of the studies that established a thorough scale to measure SCM practices despite the abundance of studies on the influence on business performance by practicing SCM. Within the scope of this paper, the scale is constructed based on the inheritance of the essentials of the remarkable project by Li et al. $(2005,2006)$.

Initially, Li et al. (2005) proposed a model with six factors, including: (i) strategic supplier partnership; (ii) customer relationship; (iii) information sharing; (iv) information quality; (v) internal lean practice; and (vi) postponement. Li et al. (2006) modified the model by coming up with four factors and excluding the factors of internal lean practice and postponement. According to Li et al. (2006), SCM practices should concentrate on the relationship of the firm with the upstream and downstream of the chain, rather than the internal factors. Moreover, the factor practicing the internally simplified system was solely suitable for the manufacturing business and the factor the postponement in manufacture was also dependent on the type of product and market features (Fisher, 1997; Rawlinson, 1993; Pagh \& Cooper, 1998). "The postponement" corresponded with the product with high innovative capability, high degree of specialization and small size of manufacturing and logistic facilities (Li, 2006). Empirical evidence from this study also supports the scale of SCM practice with four factors, comprising: (i) strategic supplier partnership; (ii) customer relationship; (iii) information sharing; (iv) information quality. Recently, Lopes de Sousa Jabbour (2011), based on the previous studies, synthesized the valid measurements into a new scale with four elements including supply chain integration, information sharing, strategic relationship with customers and suppliers, and support customer order.

As compared with the preceding studies, the scale contributed by Li et.al (2006) contains the entire elements of SCM, from the upstream and downstream of the chain to the internal matters. Literature review indicated 613 papers that adhered the essentials from the scale of Li et al. $(2005,2006)$. A minority of scholars attempted to modified or even proposed the completely distinctive scale but Li et al.'s scale of SCM practice was perceived as the widely accepted model. For instance, Halley and Beaulieu (2010) proposed a model that exclusively applied to the manufacturing firms. The measurement concentrated on the relationship of a firm with its partners rather than the entire supply chain with the upstream and the downstream actors. Lopes de Sousa Jabbour (2011) strove to establish a measurement of SCM practice, following a proper scientific process. The measurement was appraised as a simple integration of the previous scales, with the absence of practical deployment in SCM practices studies. 
To be concluded, the paper exploits four factors from the study of Li et al. (2006) to investigate the SCM practice, sharing the similar opinion with Li et al. (2006) that the factors " 1 " and " 2 " are solely favourable for manufacturing organizations. These two factors were also eliminated in many studies with the firms from the service industry such as Banerjee and Mishra (2015) on SCM practices in Indian retail industry, Metilda and Vivekanandan (2011) on SCM practices in retail supermarket in India, and Tan (2012) on the public hospital service in Malaysia. In the context of this study, the sample comprises the enterprises from the variety of industries, excluding those two factors corresponded with the disposition of Li et al. (2006) and the preceding studies.

SCM practice measurement in this study is based on the study of Li et al. (2006) with four factors including: (i) strategic supplier partnership, referred to the long-term relationship between organizations and their suppliers; (ii) customer relationship, accounted the feedback and complaint management from the customers; (iii) information sharing, inferred as the limit and occupancy of information that is communicated to a single unit of the chain; and (iv) quality of information considered the "accuracy, timeliness, adequacy, and credibility" of the exchanged information.

\section{Results}

\subsection{Sample statistical description}

In terms of collecting data, the author co-operated with the New Enterprise Association to handle the questionnaires. Sample included the managers and the board leaders of these enterprises, who managed the entire aspects of SCM practices within firms. The responses were 173 over 500 questionnaires issued. After excluding the inadequate ones, 148 eligible questionnaires included three types of enterprise comprising private, limited and joint stock company, in which most of them were small sized enterprise with less than 100 employees (Figures 1, 2). 


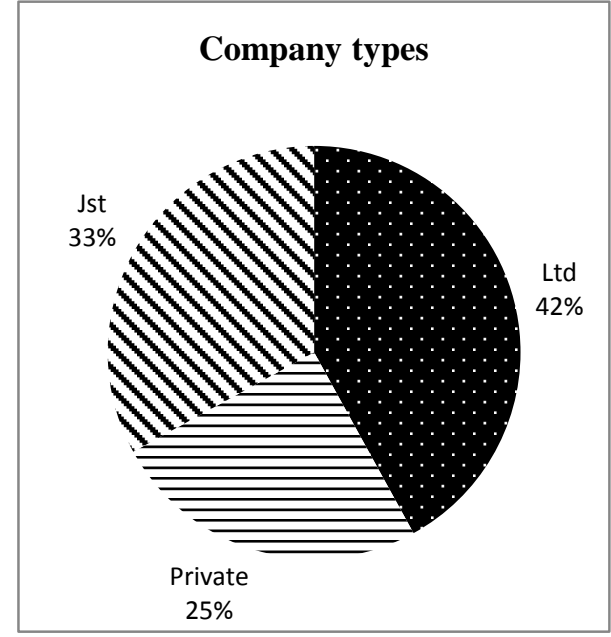

Figure 1. Sampling ratio company type ratio

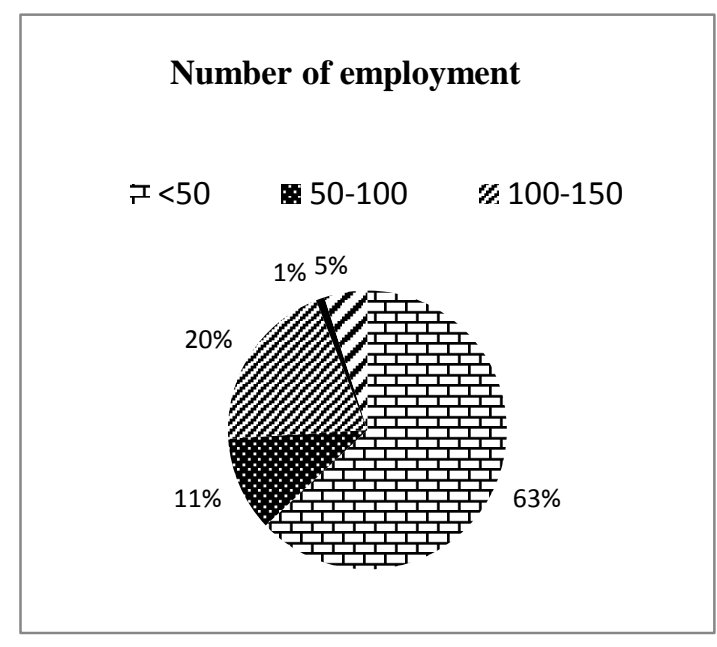

Figure 2. Number of employment sampling ratio

\subsection{Reliability of the scales}

The paper utilizes the research model by Li et al. (2006) to measure SCM practices. Results of Cronbach's Alpha analysis are presented below:

\section{Table 1}

Assessment of reliability

\begin{tabular}{lccc}
\hline Factors/Constructs & & Indicators & Reliability (a) \\
\hline Strategic Supplier Partnership & SSP & 6 & 0.685 \\
Customer relationship & CR & 5 & 0.690 \\
Information Sharing & IS & 6 & 0.755 \\
Information Quality & IQ & 5 & 0.897 \\
\hline
\end{tabular}

Overall, four factors of the scale assured their reliability with the Cronbach's Alpha indicators 0.68 . In order to evaluate the reliability of the scale, CFA analysis is employed with Amos 16. With $\chi=295.316 ; \mathrm{P}=0.00 ; \mathrm{GFI}=0.854$; $\mathrm{AGFI}=0.818$; NFI=0.779; RMESA=0.056; results indicate the reliability of the scale in measuring the SCM pratices at enterprises in Danang.

\subsection{SCM practices in Danang SMEs}

The average values of the indicators and factors are calculated in order to describe the degree of SCM practices in Danang enterprises. Overall, the majority of average values are significantly small, excluding the traditional forms of SCM practices as (SSP3), customer 
interaction (CR2), customer satisfaction measurement (CR4) with the average value over 3.

In terms of SSP, the enterprise solely considered selecting their supplier, without any strategic collaboration with the suppliers. SSP5, SSP6 indicated the involvement of both suppliers and organization with each other with 1.76 and 1.89 in value respectively. The findings imply the possibly underlying reasons that informed the issues of SMEs in Danang on the higher cost of input and unstable supply.

The "custormer relationship" indicators represent the value of approximately 3.0. This value reflects the increasing awareness of enterprises on the role of customers. Business organizations has been focusing on measurement and evaluation of the satisfaction, demand and expectation of customers.

The information sharing of partners on the chain is the most fragile matter among SMEs in Danang. Information sharing, on the collaborative activities, is not processed amid the partners on the chains (IS4, IS5). The enterprises tend to operate independently, with the lack of confidence, as a consequence, the information is supposed to be precious and needs to be kept in secrecy.

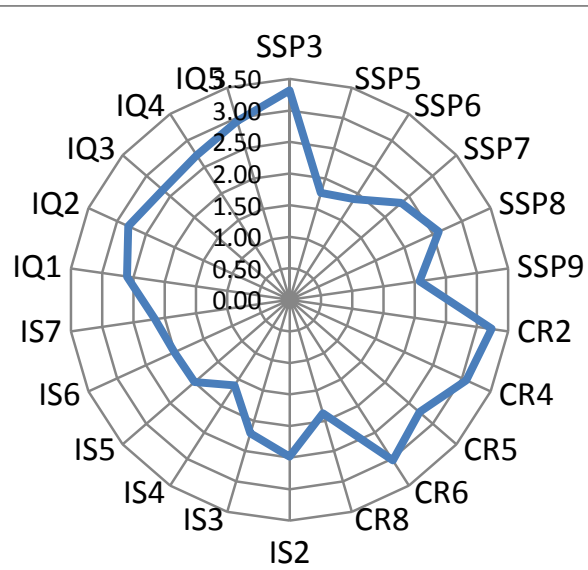

Figure 3. Findings on SCM practices in Danang enterprises

\section{Table 2e}

Means value on SCM practices in Danang enterprises

\begin{tabular}{llc}
\hline & Instruments & Mean \\
SSP & Strategic supplier partnership & 2.80 \\
SSP3 & We consider quality as our number one criterion in selecting suppliers & 3.32 \\
SSP5 & We regularly solve problems jointly with our suppliers & 1.76 \\
SSP6 & We have helped our suppliers to improve their product quality & 1.89 \\
SSP7 & We have continuous improvement programs that include our key suppliers & 2.34 \\
\hline
\end{tabular}


SSP8 We include our key suppliers in our planning and goal-setting activities

SSP9 We actively involve our key suppliers in new product development processes

CR Customer relationship

CR2

We frequently interact with customers to set reliability, responsiveness, and other standards for us

CR4 We frequently measure and evaluate customer satisfaction

CR5 We frequently determine future customer expectations

CR6 We facilitate customers' ability to seek assistance from us

CR8 We periodically evaluate the importance of our relationship with our customers

IS Information sharing

IS2 We inform trading partners in advance of changing needs

IS3 Our trading partners share proprietary information with us

Our trading partners keep us fully informed about issues that affect our business

Our trading partners share business knowledge of core business processes with us

We and our trading partners exchange information that helps establishment of business planning

We and our trading partners keep each other informed about events or changes that may affect the other partners

IQ Information Quality

IQ1 Information exchange between our trading partners and us is timely

IQ2 Information exchange between our trading partners and us is accurate

IQ3 Information exchange between our trading partners and us is complete

IQ4 Information exchange between our trading partners and us is adequate Information exchange between our trading partners and us is reliable

Data analysis demonstrates the humble degree of SCM practices among enterprises in Danang with the lack of consideration and the proper processes in practicing SCM. SMEs mainly maintain the bilateral relationship with their supplier and customer, without any 
long-term strategic considerations. Especially, the relationship with the upstream actors is significantly minor. The actor within the chain tends to keep information in secrecy and planning their operations individually, with the shortage of any further deliberations to other firms on the chain. The difficulties in their operation are properly informed by the limitations in practicing SCM and SMEs might attempt to create and maintain an effective supply chain in order to decipher these difficulties.

\section{Conclusion and policy implication}

The research findings suggest that it is necessary for SMEs to form the strategic collaboration with the suppliers and improve the information sharing process with their partners, in order to manage their supply chain effectively.

\subsection{Strategic collaboration with the suppliers}

SMEs maintain the minor position over the supplier due to their size. Power over supplier influences on the quality of the relationship with the supplier (Chicksand, 2015). The imbalance of power leads to the imbalance in benefits and risks taking responsibilities, the actor with greater power usually manipulates the benefits and risk (Cowan et al., 2015). SMEs normally can not deploy any advantages over their suppliers. Moreover, this context leads to the tendency that SMEs avoid establishing the relationship with sizeable suppliers which have the overwhelming power (van Donk \& Pieter, 2005). Lesser demand of SMEs also limits their economic of scale. Within the SMEs in Danang, the suppliers avoid participating with SMEs to come up with the solution, and SMEs also could not be able to involve in improving the product quality of suppliers (data in Section 4.3).

SMEs could lower their disadvantages by establishing the peer connection to balance the power with sizeable partners following the model of Udomleartprasert (2003). Precisely, SMEs could associate with each other to create a supplying hub to reinforce the demand of each SME within the association. The supplying hub extends the diversity of supply source, time and cost saving, the balance of price and the better supplying opportunities for SMEs (van der Vaart \& Taco, 2006). The supplying hub facilitates the sharing facilities as means of loading and transportation, that in turn, assists the economics of scale and strengthens the power of SMEs over their suppliers. 


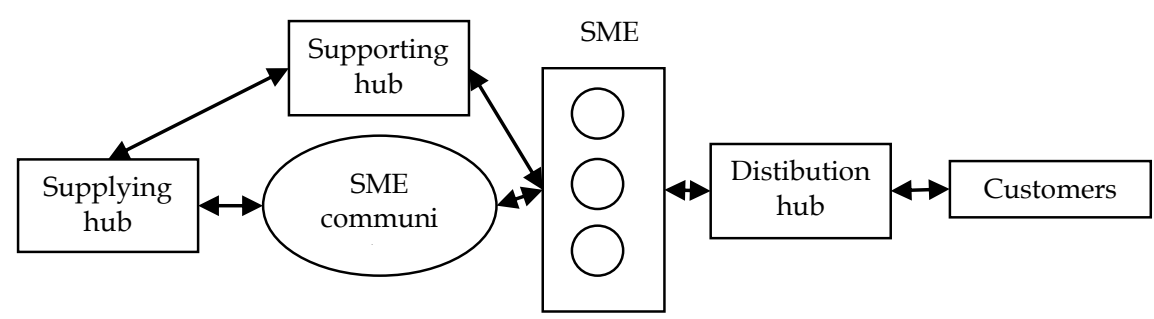

Figure 4. SCM collaboration model for SMEs

Source: Udomleartprasert (2003)

SMEs could also collaborate to effectively distribute their products and services to the ending consumers. Instead of investing in an independent distributive channel, SME could collaborate to share the distribution system and sale forces in order to recede the cost of investment and distributive management process.

\subsection{Information sharing}

Information sharing is a fundamental weakness in practicing SCM of SMEs in Danang. Information sharing is an unreplaceable premise to maintain an authentic supply chain, especially it sustains the collaborative relationship among the members of the chain. Min and Soonhong (2004) suggested that information sharing is the central of collaboration in a supply chain, the quality of the collaboration depends on the degree of information sharing in the chain. Information sharing was defined as "the distribution of useful information among people and organizations altogether" (Shuang, 2005). The information sharing decision includes two questions: the content of information and the object that receive the information.

The first element, "the object that receives the information", Kumar \& Pugazhendhi (2012) suggested that it depends on the structure of the chain, "How many connections we establish with the upstream and the downstream of the chain? The next one, "the content of information", Huang, Jason, and Lau (2003) indicated five sources of information on the chain including: (i) product; (ii) manufacturing process; (iii) inventory; (iv) order; and (v) planning. Each type of information contributes the difference benefits in sharing, for instance, "Order" information sharing support the quality management of customer service, speeding up the order process, and the information sharing on the sale of product will decrease the Bullwhip effect (Lee, 2000).

However, to successfully and effectively sharing information, SMEs are required to: (i) invest in ICT infrastructure, especially in security system; (ii) the commitment of the toplevel management and transparent strategy; (iii) solving the incompatibility of the ICT infrastructure, the awareness and the understandings on the information of partners; and (iv) establishing the confidence, and risk-taking among the partners (Shuang, 2005). 


\subsection{The support from the government}

In order to deploy the theory into practice, both local government and business community need to enforce a number of solutions and policies. Firstly, the study indicates the humble degree of SCM practices among SMEs, so it is necessary to increase the awareness of SCM from the SMEs perspective. The government would support in the aspect of training and providing information to SMEs to raise the understandings on the importance of SCM among SMEs, as well as the organizing process to deploy SCM.

Secondly, the assistance might come from the infrastructure aspect, especially with the ICT infrastructure. SCM practices require the enterprise an effective information management system from SMEs.

Thirdly, while SMEs partly recognized the importance of collaboration, alliance and association, it is not simple for SMEs to solely enforce the co-operative activities. In this case, the support of government might arise from the reinforcement to establish the peer and vertical linkages among SMEs. The government should nurture the environment that stimulates the collaboration. For instance, in 2014-2015, Danang regularly processed the "supply-demand connection" program. Despite the great effort from the government and associations, the program needed further development.

The last suggestion is over the operational quality of the associations. The quantity of associations is considerable, but their operations involved the surface solely. The activities should be focused on improving operational quality, by supporting the peer connection for SMEs, in order to reinforce their power position on the chain.

\section{Conclusion}

SCM is an up-to-date means of management and believed to bring values to organizations. In the hypercompetitive business environment and the globalization, the competition occurs in the scope of supply chain rather than individual firm level (Cigolini et al., 2004). With the understadings on the benefits of SCM to SMEs as well as the barriers in practicing SCM within SMEs in Danang, the paper suggests the implementation of SCM practices as a necessity for SMEs in Vietnam, and Danang particularly, to survive and develop in the international level competition

\section{References}

Acs, Z. J., \& David, B. A. (1991). R\&D, firm size and innovative activity. Innovation and Technological Change: An International Comparison, 98(2), 451-456.

Alvarado, U. Y., \& Kotzab, H. (2001). Supply chain management: The integration of logistics in marketing. Industrial Marketing Management, 30(2), 183-198. 
Aragón-Correa, J., \& Alberto, E. A. (2008). Environmental strategy and performance in small firms: A resource-based perspective. Journal of Environmental Management, 86(1), 83-103.

Banerjee, M., \& Mishra, M. (2015). Retail supply chain management practices in India: A business intelligence perspective. Journal of Retailing and Consumer Services, 2014, 1-12. http:/ / doi.org/10.1016/j.jretconser.2015.09.009

Banfield, E. (1994). Harnessing value in the supply chain: Strategic sourcing in action. Vol. 4. John Wiley \& Sons.

Bidgoli, H. (2010). The handbook of technology management, supply chain management, marketing and advertising, and global management. Vol. 2. John Wiley \& Sons.

Chang, W., Ellinger, A. E., Kim, K. K., \& Franke, G. R. (2016). Supply chain integration and firm financial performance: A meta-analysis of positional advantage mediation and moderating factors. European Management Journal, 34(3), 282-295. http:/ / doi.org/10.1016/j.emj.2015.11.008

Chardine-Baumann, E., \& Botta-Genoulaz, V. (2014). A framework for sustainable performance assessment of supply chain management practices. Computers $\mathcal{E}$ Industrial Engineering, 76, 138-147. http://doi.org/10.1016/j.cie.2014.07.029

Chen, I. J., \& Paulraj, A. (2004). Towards a theory of supply chain management: The constructs and measurements. Journal of Operations Management, 22(2), 119-150. http://doi.org/10.1016/j.jom.2003.12.007

Chicksand, D. (2015). Partnerships: The role that power plays in shaping collaborative buyer-supplier exchanges. Industrial Marketing Management, 48, 121-139.

Chin, T. A., Hamid, A. B. A., Rasli, A., \& Baharun, R. (2012). Adoption of supply chain management in SMEs. Procedia - Social and Behavioral Sciences, 65(1), 614-619. http:/ /doi.org/http://dx.doi.org/10.1016/j.sbspro.2012.11.173

Choon Tan, K., Lyman, S. B., \& Wisner, J. D. (2002). Supply chain management: A strategic perspective. International Journal of Operations \& Production Management, 22(6), 614-631.

Chopra, S., \& Meindl, P. (2014). Supply chain management: Strategy, planning and operation. Pearson.

Cigolini, R., Cozzi, M., \& Perona, M. (2004). A new framework for supply chain management. International Journal of Operations \& Production Management, 24(1), 7-41. http://doi.org/10.1108/01443570410510979

Cowan, K., Audhesh, K. P., \& Enid, V. S. (2015). When inter-firm relationship benefits mitigate power asymmetry. Industrial Marketing Management, 48, 140-148.

De Toni, A., \& Nassimbeni., G. (1996). Strategic and operational choices for small subcontracting firms: Empirical results and an interpretative model. International Journal of Operations \& Production Management, 16(6), 41-55.

Ellegaard, C., \& Ritter, T. (2006). The concept of attraction: Its purchasing potential. The 15th 
Annual IPSERA Conference. San Diego.

Fisher, J., Raman, A., Hammond, M., \& Obermeyer, W. (1997). Configuring a supply chain to reduce the cost of demand uncertainty. Production and Operations Management, 6(3), 211-225.

Fuller, J. B., O'Conor, J., \& Rawlinson, R. (1993). Tailored logistics: The next advantage. Harvard Business Review, 71(3), 87-98.

Gourova, E. (2010). Knowledge management strategy for small and medium enterprises. Proceedings of the International Conference on Applied Computer Science. Malta, 1517 September, 2010.

Ha, V. H. (2012). Value chain of Vietnam textile exports: Disadvantages and measures (in Vietnamese). Journal of Science-National University Hanoi, 28(4).

Halley, A., \& Beaulieu, M. (2010). A multidimensional analysis of supply chain integration in canadian manufacturing. Canadian Journal of Administrative Sciences, 27(2), 174-187. http:/ / doi.org/10.1002/cjas.144

Harland, C. M., Lamming, R. C., \& Cousins, P. D. (1999). Developing the concept of supply strategy. International Journal of Operations \& Production Management, 19(7), 650-674.

Huang, G. Q., Jason, S. K., \& Lau, K. L. M. (2003). The impacts of sharing production information on supply chain dynamics: A review of the literature. International Journal of Production Research, 41(7), 1483-1517.

Kalafatis, S. P., Markos, H., \& Tsogas, C. B. (2000). Positioning strategies in business markets. Journal of Business \& Industrial Marketing, 15(6), 416-437.

Koh, S. C. L., Demirbag, M., Bayraktar, E., Tatoglu, E., \& Zaim, S. (2007). The impact of supply chain management practices on performance of SMEs. Industrial Management $\mathcal{E}$ Data Systems, 107(1), 103-124. http:/ / doi.org/10.1108/02635570710719089

Kumar, R. S., \& Pugazhendhi, S. (2012). Information sharing in supply chains: An overview. Procedia Engineering. http:/ / doi.org/10.1016/j.proeng.2012.06.258

Lazarica, M. (2009). The virtual enterprise: Opportunity for SMEs in the digital economy. Annals, Economic Science Series, Vol. 15, pp. 501-505.

Lee, H. L., \& Wang, S. (2000). Information sharing in a supply chain. International Journal of Manufacturing Technology and Management, 1(1), 79-93.

Lenny Koh, S. C., Demirbag, M., Bayraktar, E., Tatoglu, E., \& Zaim, S. (2007). The impact of supply chain management practices on performance of SMEs. Industrial Management $\mathcal{E}$ Data Systems, 107(1), 103-124. https:/ / doi.org/10.1108/02635570710719089

Levy, M. (2001). SMEs: Aligning IS and the strategic context. Journal of Information Technology, 16(133-144).

Levy, M., \& Weitz, B. A. (2001). Retailing management. McGraw-Hill Education.

Li, S., Ragu-Nathan, B., Ragu-Nathan, T., \& Rao, S. S. (2006). The impact of supply chain 
management practices on competitive advantage and organizational performance. Omega. Retrieved from http://www.sciencedirect.com/science/article/pii/S0305048304001343

Li, S., Rao, S., Ragunathan, T., \& Ragunathan, B. (2005). Development and validation of a measurement instrument for studying supply chain management practices. Journal of Operations Management, 23(6), 618-641. http://doi.org/10.1016/j.jom.2005.01.002

Lopes, S. J., Gomes, A. F., Viana, A. N., \& José, C. J. (2011). Measuring supply chain management practices. Measuring Business Excellence, 15(2), 1831. https:// doi.org/10.1108/13683041111131592

Metilda, R. M., \& Vivekanandan, K. (2011). Impact of supply chain management practices on the competitive advantage of Indian retail supermarkets. International Journal of Logistics Systems and Management, 9(2), 170-185. http://doi.org/10.1504/IJLSM.2011.041504

Min, S., \& Mentzer, J. T. (2004). Developing and measuring supply chain management concepts. Journal of Business Logistics, 25(1), 63-99.

Mohanty, R. P., \& Deshmukh, S. G. (2005). Supply chain management (theories \& practices). John Wiley \& Sons.

New, S. J., \& Payne., P. (1995). Research frameworks in logistics: Three models, seven dinners and a survey. International Journal of Physical Distribution \& Logistics Management, 25(10), 60-77.

Nguyen, H. T. (2010). Increasing the performance of SMEs in supply chains of large enterprises: An SME perspective. Master's Thesis in Logistics and Innovation Management. Mekdes Belihu. August 2010.

Okongwu, U., Lauras, M., François, J., \& Deschamps, J. C. (2016). Impact of the integration of tactical supply chain planning determinants on performance. Journal of Manufacturing Systems, 38, 181-194. http:// doi.org/10.1016/j.jmsy.2014.10.003

Olhager, J., \& Selldin, E. (2004). Supply chain management survey of Swedish manufacturing firms. International Journal of Production Economics, 89(3), 353-361. http://doi.org/10.1016/S0925-5273(03)00029-X

Pagell, M. (2004). Understanding the factors that enable and inhibit the integration of operations, purchasing and logistics. Journal of Operations Management, 22(5), 459-487.

Pagh, J. D., \& Cooper, M. C. (1998). Supply chain postponement and speculation strategies: How to choose the right strategy. Journal of Logistics Management, 19(2), 13-33.

Sukati, I., Abdul Hamid, A. B., Baharun, R., Tat, H. H., \& Said, F. (2011). A study of supply chain management practices: An empirical investigation on consumer goods industry in Malaysia. International Journal of Business and Social Science, 2(17), 166-176. Retrieved from http://www.ijbssnet.com

Sukati, I., \& Hamid, A. (2012). Competitive advantage through supply chain responsiveness 
and supply chain integration. International Journal of Business and Commerce, 1(7), 1-11. Retrieved from http://www.internationalconference.com.my/proceeding/ icber2012_proceeding/165_123_3rdICBER2012_Proceeding_PG2402_2412.pdf

Sun, S. (2005). Information supply chain: A unified framework for information-sharing. International Conference on Intelligence and Security Informatics. Springer Berlin Heidelberg.

Tan, C. L. (2012). The effect of service supply chain management practices on the public healthcare organizational performance. International Journal of Business and Social Science, 3(16), 216-225.

Tan, K. C. (2001). A framework of supply chain management literature. European Journal of Purchasing $\mathcal{E}$ Supply Management, 7(1), 39-48. http://doi.org/10.1016/S09697012(00)00020-4

Tan, K. C., Kannan, V. R., \& Handfield, R. B. (1998). Supply chain management: supplier performance and firm performance. Journal of Supply Chain Management, 34(3).

Udomleartprasert, P. (2003). Operational infrastructure enhancing the supply chain management. International Conference of Electronic Business, Singapore, 2003.

van der Vaart, T. \& Taco, D. B. (2006). Buyer-focused operations as a supply chain strategy: Identifying the influence of business characteristics. International Journal of Operations $\mathcal{E}$ Production Management, 26(1), 8-23.

van der Vaart, T., \& van Donk, D. P. (2008). A critical review of survey-based research in supply chain integration. International Journal of Production Economics, 111(1), 42-55. http:/ / doi.org/10.1016/j.ijpe.2006.10.011

van Donk, D., \& Dirk, P. (2005). A case of shared resources, uncertainty and supply chain integration in the process industry. International Journal of Production Economics, 96(1), 97108.

Vo, T. T. L., \& Nguyen, P. S. (2013). Solutions to enhancing the value chain of specialty rice ST5 in Soc Trang Province (in Vietnamese). Journal of Science-Can Tho University, 27, 2533. 